\title{
Attitudes towards preventive tuberculosis treatment among hospital staff
}

Vidya Pathak, Zinta Harrington, Claudia C Dobler

Background Healthcare workers have an increased risk of latent tuberculosis infection (LTBI), but previous studies suggested that they might be reluctant to accept preventive tuberculosis (TB) treatment. We aimed to examine doctors' and nurses' experience of TB screening and to explore their attitudes towards preventive TB treatment. Methods We conducted a survey among randomly selected healthcare workers at a tertiary hospital in Sydney, Australia, using a paper-based questionnaire. Results A total of 1304 questionnaires were distributed and 311 (24\%) responses were received. The majority of hospital staff supported preventive TB treatment in health care workers with evidence of latent TB infection (LTBI) in general $(74 \%, 164 / 223)$ and for them personally $(81 \%$, 198/244) while 80 and 53 healthcare workers respectively had no opinion on the topic. Staff working in respiratory medicine were significantly less likely to support preventive TB treatment in health care workers in general or for them personally if they would have evidence of LTBI compared to other specialties $(p=0.001)$. Only $13 \%(14 / 106)$ of respondents with evidence of $L T B I$ indicated that they had been offered preventive TB treatment. Twenty-one per cent (64/306) of respondents indicated that they did not know the difference between active and latent TB. Among staff who had undergone testing for LTBI, only 33\% (75/230) felt adequately informed about the meaning of their test results. Discussion Hospital staff in general had positive attitudes towards preventive TB treatment, but actual treatment rates were low and perceived knowledge about LTBI was insufficient among a significant proportion of staff. The gap between high support for preventive TB treatment among staff and low treatment rates needs to be addressed. Better education on the concept of LTBI and the meaning of screening test results is required. 


\section{Attitudes towards preventive tuberculosis treatment among}

\section{2 hospital staff}

3 Vidya Pathak ${ }^{1,2}$, Zinta Harrington ${ }^{1,2}$, Claudia C. Dobler ${ }^{1,2}$

$4 \quad{ }^{1}$ South Western Sydney Clinical School, University of New South Wales, Sydney, New South

5 Wales, Australia

$6 \quad{ }^{2}$ Department of Respiratory Medicine, Liverpool Hospital, Sydney, New South Wales, Australia

7 Corresponding Author:

8 Dr Claudia Dobler

9 Department of Respiratory and Sleep Medicine

10 Liverpool Hospital

11 Liverpool (Sydney), NSW 1871, Australia

12 Telephone

(02) 8738-4101

13 Email Address

c.dobler@unsw.edu.au

14 Zinta Harrington zintah@bigpond.com

15 Vidya Pathak z3372408@zmail.unsw.edu.au 


\section{Abstract}

17 Background Healthcare workers have an increased risk of latent tuberculosis infection (LTBI), but previous studies suggested that they might be reluctant to accept preventive tuberculosis (TB) treatment. We aimed to examine doctors' and nurses' experience of TB screening and to explore their attitudes towards preventive TB treatment.

21 Methods We conducted a survey among randomly selected healthcare workers at a tertiary hospital in Sydney, Australia, using a paper-based questionnaire.

Results A total of 1304 questionnaires were distributed and 311 (24\%) responses were received. The majority of hospital staff supported preventive TB treatment in health care workers with evidence of latent TB infection (LTBI) in general $(74 \%, 164 / 223)$ and for them personally $(81 \%$, 198/244) while 80 and 53 healthcare workers respectively had no opinion on the topic. Staff working in respiratory medicine were significantly less likely to support preventive TB treatment in health care workers in general or for them personally if they would have evidence of LTBI compared to other specialties $(\mathrm{p}=0.001)$. Only $13 \%(14 / 106)$ of respondents with evidence of LTBI indicated that they had been offered preventive TB treatment. Twenty-one per cent (64/306) of respondents indicated that they did not know the difference between active and latent TB. Among staff who had undergone testing for LTBI, only 33\% (75/230) felt adequately informed about the meaning of their test results.

Discussion Hospital staff in general had positive attitudes towards preventive TB treatment, but actual treatment rates were low and perceived knowledge about LTBI was insufficient among a significant proportion of staff. The gap between high support for preventive TB treatment among staff and low treatment rates needs to be addressed. Better education on the concept of LTBI and the meaning of screening test results is required. 
Introduction

41 Australia has a low incidence of tuberculosis (TB), with an incidence of 6.0 per 100000

42 population per year (Barry et al. 2012). However, ongoing TB control efforts are warranted given

43 high levels of immigration from settings with a high incidence of TB. Also, a significant number

44 of migrants from TB endemic areas work in the Australian health system. Healthcare workers

45 (HCWs) have been shown to be at an increased risk of having latent (dormant) tuberculosis

46 infection (LTBI). The Melbourne Mantoux Study that was conducted in the late 1990s showed

47 that $19.3 \%$ of HCWs in teaching hospitals in Melbourne had positive tuberculin skin tests (TSTs),

48 compared to $13.7 \%$ of non-HCWs $(\mathrm{p}<0.001)$ (Stuart et al. 2001). The risk of developing active

49 TB disease from LTBI is of concern in HCWs, as sick HCWs could pass the TB infection on to

50 vulnerable patients. People with LTBI can receive preventive TB treatment, which usually

51 consists of a 6 to 9 month course of daily isoniazid tablets. However, this treatment is associated

52 with a potential risk of drug-induced hepatitis, which varies from 0.1 to $2.4 \%$ (depending on age)

53 for hepatitis requiring hospitalisation (Smith et al. 2011).

54 While the efficacy of isoniazid preventive therapy has been clearly demonstrated, (Ayieko et al.

55 2014; Smieja et al. 2000; World Health Organization 1982) HCWs have been shown to be

56 significantly more reluctant to accept treatment for LTBI than non-HCWs (Barrett-Connor 1979;

57 Camins et al. 1996; Geiseler et al. 1987; Gershon et al. 2004; LoBue \& Catanzaro 1998;

58 Ramphal-Naley et al. 1996; Xu \& Schwartzman 2010). HCWs have lower rates of initiation of

59 treatment for LTBI and may face specific issues when undergoing screening for LTBI, such as

60 scepticism towards medical testing and difficulties scheduling a screening appointment when

61 doing shift work (Joseph et al. 2004; Ramphal-Naley et al. 1996). The exact reasons for lower

62 uptake of this evidence-based intervention among HCWs remain unclear. 
63 The aim of this study was to examine HCWs experiences of TB screening and their attitudes

64 towards preventive TB treatment at a tertiary hospital in Sydney, Australia.

\section{Materials \& Methods}

\section{Study setting and population}

67 The study was performed at Liverpool Hospital, a tertiary hospital with a major TB clinic in

68 Sydney. Liverpool Hospital TB clinic treats approximately $10 \%$ of all TB patients in Australia

69 and $20 \%$ of all patients in the state of New South Wales (NSW). In this setting, the TB incidence

70 is 7.3 per 100000 population per year (Barry et al. 2012).

71 Since the introduction of a new policy directive on HCW screening in NSW in 2011 new HCWs

72 must only undergo TB screening if they were born in a country with a high incidence of TB, or if

73 they have travelled to a country with a high incidence of TB for three months or longer (NSW

74 Health 2011). The state policy directive defines a country with a high incidence of TB as one that

75 has a TB incidence $\geq 60$ cases per 100,000 population per year. Existing staff members who lived

76 in a country with a high incidence of TB for more than 3 months within the last 3 years must also

77 undergo TB screening.

78 During the screening process, a medical history is taken; a tuberculin skin test (TST) is

79 performed and a chest $\mathrm{x}$-ray is done if the TST is positive. The results of these investigations are

80 then reviewed by a doctor at the TB clinic, who decides whether the HCW is booked for a

81 doctor's appointment or not. When there is no evidence of active TB, the doctor will decide

82 whether to offer preventive treatment to a HCW with evidence of LTBI (usually TST $\geq 10 \mathrm{~mm}$ )

83 based on an assessment of the individual's risk of developing TB. If there is concern about a

84 possible false positive TST result (e.g. in a $\mathrm{HCW}$ who received a Bacillus Calmette-Guérin 
85 (BCG) vaccination, which is known to cause a TST cross-reaction), the doctor may also decide to

86 order an additional blood test (Interferon Gamma Release Assay (IGRA)) to confirm true LTBI.

\section{Study design}

88 A paper-based questionnaire was sent to randomly selected nurses and doctors, attached to the

89 fortnightly pay slips. Respondents were asked to return the completed questionnaire

90 anonymously in the attached return envelope. Randomisation was performed using a random

91 number generator in Microsoft Excel. Additionally, one of the researchers (VP) approached

92 doctors and nurses in person using a random starting point from a list of hospital locations

93 (including wards, outpatient clinics and clinical meetings) and then approaching every second

94 HCW. . Staff who were approached in person were asked if they had received a questionnaire

95 with the pay slip. If they indicated that they had not yet received a questionnaire, they were given

96 a questionnaire and asked to return it anonymously in the attached envelope. They were asked to

97 fill in only one questionnaire should they later discover a mailed questionnaire at home. We did

98 not have a formal control mechanism to exclude duplicate submissions from the same person.

99 The risk for duplicate submissions was, however, perceived to be very low because there was no

100 financial incentive attached to providing a response.

101 Questionnaire

102 The questionnaire for hospital staff (see supporting information) included questions on HCWs'

103 demographic background including their age, gender, profession, hospital department, level of 104 patient contact, country of birth, and history of overseas stay. Additional questions addressed the

105 personal experience with TB screening including history of BCG vaccination, results of screening

106 chest X-rays, results of TST and IGRA tests and knowledge about their personal TB status (no

107 evidence of LTBI, evidence of LTBI, active TB or past medical history of TB). Participants were 
108 asked whether they were offered treatment for LTBI and, whether they accepted treatment for

109 LTBI. They were questioned about their general opinion on treatment for LTBI.

\section{Definitions}

111 A TB incidence of $\geq 60$ per 100,000 population was chosen to define a country with a high

112 incidence of TB, as per the NSW Health Policy Directive (NSW Health 2011). Incidence rates of

113 TB were based on estimates of the World Health Organization (WHO) accessed on 01/10/2013

114 (World Health Organization). A positive screening test result was defined as having a positive

115 TST $(\geq 10 \mathrm{~mm})$ and/or IGRA. Staff working in respiratory medicine was defined as HCWs whose 116 work focused on the care of patients with respiratory problems, not just staff involved in the care 117 of TB patients. The speciality of respiratory medicine was highlighted in the study because the 118 TB clinic at the study hospital was integrated into the department of respiratory medicine.

\section{Statistical Analyses}

120 Calculation of proportion of responses was based on the total number of HCWs who answered a 121 specific question in the questionnaire, in other words, the denominator for each question was the number of staff who answered the question by ticking one of the boxes. Data were extracted from the paper-based questionnaire and entered into a Microsoft Excel database.

Logistic regression and odds ratios (ORs) with 95\% confidence intervals (95\% CIs) were used to assess associations between demographic characteristics and survey responses. The independent effect of potential predictors of survey responses among HCWs was estimated using multivariable logistic regression for binary outcomes, in which the dependent variable could take only two values, yes/no. Responses that indicated that the respondent had no opinion or did not 
130 included adjustment for age, sex, profession, specialty, country of birth, screening results, being

131 offered treatment and history of BCG vaccine. Statistically significant results were defined as $\mathrm{p}<$

132 0.05. SPSS Statistics v21 (IBM Corp, Armonk, NY) was used for the statistical analysis.

\section{Ethical approval \& Consent}

134 The study protocol was approved by the South Western Sydney Local Health District Ethics

135 Committee (project number 12/265). Attached to all questionnaires was a participant information

136 sheet which included the following information regarding participant consent: "Your participation

137 in this survey is entirely voluntary. You may choose not to take the survey, or to skip any

138 questions that you do not want to answer. Your completion of the questionnaire serves as your

139 voluntary agreement to participate in this research project."

140 Results

141 Participants

142 A total of 733 questionnaires were sent to randomly selected nurses and 431 to randomly selected

143 doctors; an additional 87 and 53 questionnaires were directly handed to nurses and doctors

144 respectively. Of $1304 \mathrm{HCWs}$ who received a questionnaire, 318 responded, resulting in a

145 response rate of $24 \%$. Seven responses were excluded because the questionnaires were blank, so

146311 responses were included in the analysis. The response rate was $22 \%(105 / 484)$ among

147 doctors and 25\% (206/820) among nurses. Forty-seven per cent (144/307) of respondents were

148 Australian-born. Ninety-five per cent of respondents (295/311) had undergone TB screening,

149 including 151who had undergone screening at the hospital's TB clinic. The majority (225) had

150 undergone screening prior to February 2011, when a new screening policy for HCWs was

151 introduced in NSW, limiting TB screening to HCWs considered to be at risk of previous TB 
152 infection. Table 1 summarizes the demographic characteristics of all HCWs who participated in 153 the study.

\section{Experience with screening for latent TB infection at the hospitals' TB clinic}

155 Of the 295 HCWs who underwent screening, 258 (87\%) reported having undergone TST and/or 156 IGRA testing (Fig 1). Of those who underwent a TST and/or IGRA test, 116 (45\%) indicated that

157 they had a positive screening test result suggestive of LTBI, of which 10 (9\%) did not answer the 158 question on whether they were offered treatment for LTBI or not. Only 13\% (14/106) of HCWs 159 with evidence of LTBI indicated that they were offered preventive TB treatment; 40\% (42/106) 160 were not offered treatment, and 47\% (50/106) felt that this question did not apply to them. Sixty-

161 four per cent of HCWs $(9 / 14)$ accepted the offered preventive TB treatment. HCWs who refused 162 treatment felt that they could monitor signs and symptoms of TB themselves (3/5); stated they 163 feared side effects $(2 / 5)$, felt that the treatment was unnecessary $(2 / 5)$ and stated that they did not 164 need treatment as they had been vaccinated (1/5).

\section{Attitudes towards preventive TB treatment}

166 Of the respondents who expressed an opinion on the topic, 74\% (164/223) supported the idea that did not think that preventive TB treatment was indicated in this situation. A further 80 respondents did not express any opinion on the topic.. In bivariate logistic regression analysis there was a positive association between support for preventive TB treatment for employees in non-respiratory specialties (OR 7.83, 95\% CI $2.27-22.51$ for staff in medical specialties other than respiratory medicine and OR $20.8395 \%$ CI 4.53 - 95.89 for surgical staff, compared to

173 respiratory staff). There were also associations between support for preventive TB treatment and 174 female gender (OR 1.94, 95\% CI 1.05 - 3.61), nursing staff (OR 2.36, 95\% CI 1.28 - 4.34) and 
175 positive TST status (OR $2.4195 \%$ CI 1.21 - 4. $\underline{\text { 82) }}$ ). In multivariable logistic regression, only the

176 respondent's specialty had a significant association with a favourable attitude towards preventive

177 TB treatment. Staff from non-respiratory specialties were more supportive of preventive TB

178 treatment than respiratory staff (aOR 8.62, 95\% CI $2.69-27.61$ for staff in other medical

179 specialties and aOR 16.94 95\% CI 3.22 - 89.05 for surgical staff) (Table 2).

180 Eighty-one per cent (198/244) of respondents were in favour of being offered preventive TB 181 treatment if they had evidence of LTBI personally and 19\% (46/244) preferred not be offered 182 preventive TB treatment personally. Another 53 respondents had no opinion on the topic. There 183 was greater support for personal preventive TB treatment among staff from non-respiratory staff 184 compared to respiratory staff $(85 \%, 187 / 221$ versus $48 \%, 11 / 23$ respectively (Table 2$))$. The 185 specialty hospital staff worked in was the only characteristic that was significantly associated 186 with the attitude towards personal preventive TB treatment in bivariate and multivariable logistic 187 analyses.

188 The majority of respondents $(70 \%, 185 / 264)$ stated they would require more information to 189 decide whether they personally would want to receive preventive TB treatment if they had 190 evidence of LTBI, 30\% (79/264) felt that they were sufficiently informed and a further 31 had no 191 opinion on the topic.

192 The majority of respondents who expressed an opinion $(73 \%, 200 / 273)$ thought that Australian 193 born HCWs without significant overseas stay should be screened for LTBI; 26\% (73/273) thought 194 that they should not be screened. A further 34 respondents voiced no opinion. A third of 195 respiratory staff (9/27) believed that these HCWs should be screened, compared to 78\% $196(191 / 246)$ of those in other specialities. 
197

198 Twenty-one per cent of respondents (64/306) indicated that they did not know the difference

199 between active and latent TB. Only $69 \%$ of respondents aged 30 years or less thought that they

200 knew the difference compared to $89 \%$ of those in the 31 to 40 years age group (aOR $3.32,95 \%$

201 CI 1.23 - 8.99) (Table 3). Nurses were less likely to indicate that they knew the difference than 202

Of the HCWs who had undergone TST and/or IGRA testing only 33\% (75/230) felt adequately informed about the meaning of their test results, 16\% (37/230) did not feel adequately informed, and $51 \%(118 / 230)$ were not even aware that the question on information about test results applied to them.

\section{Discussion}

This study, conducted at a tertiary hospital with one of the biggest TB clinics in Australia, found that hospital staff in general had positive attitudes towards preventive TB treatment, but the proportion of staff with evidence of LTBI who had been offered preventive TB treatment was low and knowledge about LTBI and the meaning of test results was insufficient.

In the current study, only $13 \%(14 / 106)$ of HCWs with evidence of LTBI indicated that they were offered preventive TB treatment. The proportion of treatment of LTBI in HCWs in other studies has ranged from 29\% to 98.4\% (Camins et al. 1996; LoBue \& Catanzaro 1998; Xu \& 
218 Schwartzman 2010). The high treatment rate of $98.4 \%$ was from a study that focused on HCWs

219 who had a TST conversion and thus were at a relatively high risk of TB reactivation (Camins et 220 al. 1996) while our study investigated routine HCW screening. Further, the studies with higher

221 proportions of preventive TB treatment among HCWs were conducted in North America,

222 (Camins et al. 1996; LoBue \& Catanzaro 1998; Shukla et al. 2002; Xu \& Schwartzman 2010)

223 where treatment of LTBI is pursued more proactively, mainly as a result of policies directed at TB 224 elimination in the USA. Two of these studies outlined that preventive TB treatment was routinely 225 offered to HCWs with evidence of LTBI, contributing to relatively high treatment rates (Camins 226 et al. 1996; Shukla et al. 2002).

227 In our study $9 / 14(64 \%)$ of staff who were offered preventive TB treatment accepted it. Studies 228 have shown proportions ranging from to $37.5 \%$ to $85 \%$ for accepting treatment (Bhanot et al. 229 2012; Camins et al. 1996; LoBue \& Catanzaro 1998; Ramphal-Naley et al. 1996; Shukla et al. 230 2002; Xu \& Schwartzman 2010). The fact that the proportion of HCWs with LTBI offered 231 treatment was clearly lower in the current study than reported in other studies, while the 232 proportion of HCWs accepting treatment lay within the range of other study findings, suggests 233 there is a service gap. Sixty-seven per cent (198/297) of respondents were in favour of being 234 offered preventive TB treatment if they personally had evidence of LTBI.

235 It is of interest in this context that staff working in respiratory medicine showed significantly 236 lower support for treatment of LTBI in HCWs in general $(22 \%, 6 / 27)$ as well as for them 237 personally $(41 \%, 11 / 27)$. More scepticism towards treatment of LTBI among respiratory staff 238 may be the result of increased awareness about potential side effects of preventive therapy with 239 isoniazid, in particular the risk of drug-induced hepatitis. A US study found that the perception 
240 that LTBI treatment was harmful was an important barrier to HCWs adherence to work site TB

241 screening and treatment policies (Joseph et al. 2004).

242 The reason why a large proportion (47\%) of respondents with a positive test for LTBI felt that the

243 question about the offer of preventive TB treatment did not apply to them was likely because the

244 majority would not have had an encounter with a TB clinician to discuss preventive TB

245 treatment, but would just have undergone the screening tests. It is possible that the question was

246 not specific enough. We believe, however, that the high proportion of health care workers with

247 evidence of LTBI who thought that the question about the offer of preventive TB treatment was

248 not relevant to them, indicates lack of awareness about the option of preventive treatment among

249 those who have likely been infected with TB.

250 Previous research in the current study setting indicated that physicians' decisions on treatment of

251 LTBI were based on individualised appraisals of risks and benefits of LTBI treatment, and that

252 there was a bias against offering treatment to people born overseas, men and HCWs (Dobler et al.

253 2013). We can only speculate about the reasons why HCWs with evidence of LTBI would not be

254 targeted more frequently for preventive TB treatment. If HCWs are seen as part of routine $\mathrm{HCW}$

255 screening (rather than as part of a contact tracing investigation), the time of infection in HCWs

256 with LTBI is usually unclear and the risk of TB reactivation is not as high as in recent TB

257 infection. Further, HCWs may be perceived to have an ongoing risk of TB exposure at the

258 workplace negating the benefits of preventive TB treatment. Importantly, there is evidence that

259 physicians are reluctant to receive preventive TB treatment themselves, (Bhanot et al. 2012)

260 possibly explaining why they would be less likely to offer it to other HCWs. A Canadian study

261 suggested that physicians and patients may be more likely to initiate treatment if they trusted that 
262 a positive TST was not just simply the result of a previous BCG vaccination, but reflected true

263 LTBI infection (Xu \& Schwartzman 2010).

264 The low rate of LTBI treatment among health care workers with evidence of LTBI in our study

265 raises the question of the purpose of LTBI screening. The American Thoracic Society (ATS) and

266 the Centers for Disease Control and Prevention (CDC) released a statement on LTBI screening

267 and treatment in the year 2000 that endorsed the principle of "intention to test is intention to

268 treat". In this statement screening for LTBI was only supported for persons at high risk for

269 developing TB (persons with presumed recent $M$. tuberculosis infection and persons with clinical

270 conditions associated with progression to active TB) who would be treated for LTBI if they had a

271 positive screening test (American Thoracic Society 2000). In many countries, including Australia,

272 however, screening for LTBI is routinely performed among all healthcare workers (or at least in

273 those with a significant stay in a TB endemic setting), even if they are not considered to be at a

274 high risk of developing TB. Thus, the "intention to test is intention to treat" principle does not

275 necessarily apply to health care workers. In Australia, the primary purpose of healthcare worker

276 screening is to exclude active TB (on chest x-ray) in persons who have a positive test for LTBI

277 and to get a "baseline" result for LTBI, which can be helpful for assessing the risk of infection in

278 case of future work-related TB exposure. The finding that $73 \%$ of respondents in our survey

279 supported that Australian born health care workers without significant overseas stay should be

280 screened for LTBI can possibly be explained in this context.

281 More than one in five respondents indicated that they did not know the difference between active

282 and latent TB. The lack of perceived knowledge was more prevalent among nurses than doctors

283 and in those aged 30 years or less. Insufficient knowledge about TB in younger HCWs could

284 possibly be a result of the relatively low incidence of TB in Australia since the 1970s or a 
285 consequence of changed education and information associated with TB screening in HCWs. Only

$28633 \%$ of staff $(75 / 230)$ felt adequately informed about the meaning of their TST and/or IGRA

287 result indicating a need for better explanation of screening test results.

288 A limitation of the study was that the survey was performed in a single hospital. However, a 289 study conducted in contacts of patients with active TB in all of New South Wales showed that 290 only $9.5 \%$ of TB contacts with evidence of LTBI received preventive TB treatment, indicating 291 that low proportions of treatment for LTBI are likely a systemic problem in New South Wales and 292 possibly beyond, rather than an issue confined to a single centre (Dobler 2013; Dobler \& Marks 293 2013). As with any survey study, participant selection bias could not be excluded. As only $24 \%$ of 294 all questionnaire recipients responded, it is possible that those with a positive test for LTBI were 295 overrepresented, as they could have been expected to have had a stronger interest in the topic of 296 TB and LTBI than those with negative test results. The respondents with evidence of LTBI were, 297 however, were likely representative of health care workers at the hospital in general in terms of 298 previous treatment experience for LTBI. A previous case-control study in the same setting 299 indicated that only $17 \%$ (16/92) of health care workers with evidence of LTBI received treatment 300 (Dobler et al. 2013), which was not significantly different from the 13\% (14/106) found in the 301 current study $(\mathrm{p}=0.48)$.

302 A further limitation was the small number of HCWs who had been offered preventive TB 303 treatment $(n=14)$, of whom only 9 had accepted treatment. These numbers were too small to show 304 significant associations between these outcomes and HCWs characteristics.

\section{Conclusions}


306 The majority of hospital staff had positive attitudes towards preventive TB treatment, but the 307 proportion of staff with evidence of LTBI who had been offered preventive TB treatment was 308 low. Perceived knowledge about LTBI was insufficient, especially among HCWs aged 30 years 309 or less and nurses. Only one third of HCWs who had undergone testing for LTBI felt adequately 310 informed about the meaning of their test results, indicating a need for better information.

311 This study has identified a gap between the demand for preventive TB treatment and the current 312 proportion of hospital staff with LTBI offered preventive treatment. This indicates the need for a 313 more pro-active and consumer-orientated approach regarding LTBI in HCWs. We suggest that 314 HCWs with evidence of LTBI should routinely be offered preventive TB treatment unless there is 315 clear concern that the risks may outweigh the benefits.

316 The study also identified room for improvement in TB health literacy, particularly, for improved 317 education about key TB concepts, such as the difference between LTBI and active TB and for 318 education about the meaning of screening test results. There is evidence that the use of 319 information leaflets can improve knowledge about TB (Roy et al. 2011). By improving the care 320 provided to HCWs with LTBI it may be possible not only to reduce active TB infections in this 321 group, but also for the vulnerable people they care for. 
322

323 324

\section{References}

American Thoracic Society. 2000. Targeted tuberculin testing and treatment of latent tuberculosis infection. . MMWR Recomm Rep 49:1-51.

Ayieko J, Abuogi L, Simchowitz B, Bukusi EA, Smith AH, and Reingold A. 2014. Efficacy of isoniazid prophylactic therapy in prevention of tuberculosis in children: a meta-analysis. BMC Infectious Diseases 14:91.

Barrett-Connor E. 1979. The epidemiology of tuberculosis in physicians. JAMA 241:33-38.

Barry C, Waring J, Stapledon R, Konstantinos A, and Committee NTA. 2012. Tuberculosis Notifications in Australia, 2008 and 2009. Communicable Disease Intelligence 36:82-94.

Bhanot N, Haran M, Lodha A, Paul V, Goswami R, and Chapnick EK. 2012. Physicians' attitudes towards self-treatment of latent tuberculosis. Int J Tuberc Lung Dis 16:169-171. 10.5588/ijtld.11.0232

Camins BC, Bock N, Watkins DL, and Blumberg HM. 1996. Acceptance of isoniazid preventive therapy by health care workers after tuberculin skin test conversion. JAMA 275:10131015.

Dobler CC. 2013. What do we know about the outcomes of tuberculosis contact investigations in NSW? N S W Public Health Bull 24:34-37. 10.1071/nb12099

Dobler CC, Luu Q, and Marks GB. 2013. What Patient Factors Predict Physicians' Decision Not to Treat Latent Tuberculosis Infection in Tuberculosis Contacts? PLoS ONE [Electronic Resource] 8:e76552.

Dobler CC, and Marks GB. 2013. Risk of tuberculosis among contacts in a low-incidence setting. Eur Respir J 41:1459-1461. 10.1183/09031936.00183812 
344 Geiseler PJ, Nelson KE, and Crispen RG. 1987. Tuberculosis in physicians. Compliance with preventive measures. American Review of Respiratory Disease 135:3-9.

Gershon AS, McGeer A, Bayoumi AM, Raboud J, and Yang J. 2004. Health care workers and the initiation of treatment for latent tuberculosis infection. Clinical Infectious Diseases 39:667-672.

Joseph HA, Shrestha-Kuwahara R, Lowry D, Lambert LA, Panlilio AL, Raucher BG, Holcombe JM, Poujade J, Rasmussen DM, and Wilce M. 2004. Factors influencing health care workers' adherence to work site tuberculosis screening and treatment policies. American Journal of Infection Control 32:456-461.

LoBue PA, and Catanzaro A. 1998. Effectiveness of a nosocomial tuberculosis control program at an urban teaching hospital. Chest 113:1184-1189.

NSW Health. 2011. Policy Directive Occupational Assessment, Screening and Vaccination Against Specified Infectious Diseases. Available at http://www0.health.nsw.gov.au/policies/pd/2011/pdf/pd2011_005.pdf(accessed 24/03/2015)

Ramphal-Naley L, Kirkhorn S, Lohman WH, and Zelterman D. 1996. Tuberculosis in physicians: compliance with surveillance and treatment. American Journal of Infection Control $24: 243-253$.

Roy A, Abubakar I, Chapman A, Andrews N, Pattinson M, Lipman M, Rodrigues LC, Figueroa J, Tamne S, and Catchpole M. 2011. A controlled trial of the knowledge impact of tuberculosis information leaflets among staff supporting substance misusers: pilot study. PLoS ONE [Electronic Resource] 6:e20875. 
366 Shukla SJ, Warren DK, Woeltje KF, Gruber CA, and Fraser VJ. 2002. Factors associated with the treatment of latent tuberculosis infection among health-care workers at a midwestern teaching hospital. Chest 122:1609-1614.

Smieja MJ, Marchetti CA, Cook DJ, and Smaill FM. 2000. Isoniazid for preventing tuberculosis in non-HIV infected persons. Cochrane Database of Systematic Reviews:CD001363.

Smith BM, Schwartzman K, Bartlett G, and Menzies D. 2011. Adverse events associated with treatment of latent tuberculosis in the general population. CMAJ Canadian Medical Association Journal 183:E173-179.

Stuart RL, Bennett NJ, Forbes AB, and Grayson ML. 2001. Assessing the risk of tuberculosis infection among healthcare workers: the Melbourne Mantoux Study. Melbourne Mantoux Study Group. Medical Journal of Australia 174:569-573.

World Health Organization. Tuberculosis Country Profile. Available at http://www.who.int/tb/country/data/profiles/en/index.html (accessed 01/10/2013 2013).

World Health Organization. 1982. Efficacy of various durations of isoniazid preventive therapy for tuberculosis: five years of follow-up in the IUAT trial. International Union Against Tuberculosis Committee on Prophylaxis. Bulletin of the World Health Organization 60:555-564.

Xu Y, and Schwartzman K. 2010. Referrals for positive tuberculin tests in new health care workers and students: a retrospective cohort study. BMC Public Health 10:28. http://dx.doi.org/10.1186/1471-2458-10-28 
387 Table 1: Characteristics of HCWs who participated in the survey

\begin{tabular}{|c|c|}
\hline Characteristic & $\begin{array}{c}\text { Total respondents } \\
\text { n=311 } \\
\mathbf{n}(\%)\end{array}$ \\
\hline \multicolumn{2}{|l|}{ Age } \\
\hline$<30$ & $75(24 \%)$ \\
\hline $31-40$ & $96(31 \%)$ \\
\hline $41-50$ & $78(25 \%)$ \\
\hline$\geq 50$ & $62(20 \%)$ \\
\hline \multicolumn{2}{|l|}{ Sex } \\
\hline Male & $90(29 \%)$ \\
\hline Female & $221(71 \%)$ \\
\hline \multicolumn{2}{|l|}{ Profession } \\
\hline Doctor & $105(34 \%)$ \\
\hline Nurse & $206(66 \%)$ \\
\hline \multicolumn{2}{|l|}{ Department $(\mathrm{n}=309)^{*}$} \\
\hline Respiratory & $28(9 \%)$ \\
\hline Other medical & $131(42 \%)$ \\
\hline Surgery & $36(12 \%)$ \\
\hline Other & $114(37 \%)$ \\
\hline \multicolumn{2}{|l|}{ Country of Birth $(\mathrm{n}=307)^{*}$} \\
\hline Australia & $144(47 \%)$ \\
\hline $\begin{array}{l}\text { Overseas from a country with a TB } \\
\text { incidence }<60 \text { per } 100000 \text { population } \\
\text { per year }\end{array}$ & $64(21 \%)$ \\
\hline $\begin{array}{l}\text { Overseas from a country with a TB } \\
\text { incidence } \geq 60 \text { per } 100000 \text { population } \\
\text { per year }\end{array}$ & $99(32 \%)$ \\
\hline
\end{tabular}

*based on the number of respondents who answered this question 
Table 2: Attitudes towards LTBI treatment among respondents by specialty ${ }^{+}$

\begin{tabular}{|c|c|c|c|c|c|c|}
\hline Question & Yes $(\%)$ & No $(\%)$ & $\begin{array}{c}\text { Unadjuste } \\
\text { d OR } \\
(95 \% \mathrm{CI})\end{array}$ & p value & $\begin{array}{c}\text { Adjusted } \\
\text { OR } \\
(95 \% \mathrm{CI})\end{array}$ & $\begin{array}{l}\text { Adjusted } \\
\text { p value }\end{array}$ \\
\hline $\begin{array}{l}\text { Do you think } \\
\text { staff who have } \\
\text { evidence of } \\
\text { LTBI should } \\
\text { receive } \\
\text { preventive } \\
\text { treatment? }\end{array}$ & & & & $\begin{array}{l}<0.001 \\
*\end{array}$ & & 0.001* \\
\hline All & $\begin{array}{r}164 / 223 \\
(74 \%) \\
\end{array}$ & $\begin{array}{r}59 / 223 \\
(26 \%) \\
\end{array}$ & & & & \\
\hline Respiratory & $\begin{array}{r}6 / 21 \\
(29 \%) \\
\end{array}$ & $\begin{array}{r}15 / 21 \\
(71 \%) \\
\end{array}$ & 1.00 (Ref) & & 1.00 (Ref) & \\
\hline Other Medical & $\begin{array}{r}72 / 95 \\
(76 \%) \\
\end{array}$ & $\begin{array}{l}23 / 95 \\
(24 \%) \\
\end{array}$ & $\begin{array}{r}7.83(2.72 \\
\text { to } 22.52) \\
\end{array}$ & $\begin{array}{r}<0.001 \\
*\end{array}$ & $\begin{array}{r}8.62(2.69 \text { to } \\
27.61) \\
\end{array}$ & $<0.001^{*}$ \\
\hline Surgery & $\begin{array}{r}25 / 28 \\
(89 \%) \\
\end{array}$ & $\begin{array}{r}3 / 28 \\
(11 \%) \\
\end{array}$ & $\begin{array}{r}20.83(4.53 \\
\text { to } 95.89) \\
\end{array}$ & $\begin{array}{r}<0.001 \\
*\end{array}$ & $\begin{array}{r}16.94(3.22 \\
\text { to } 89.05) \\
\end{array}$ & $0.001 *$ \\
\hline Other & $\begin{array}{r}61 / 79 \\
(77 \%)\end{array}$ & $\begin{array}{l}18 / 79 \\
(23 \%)\end{array}$ & $\begin{array}{r}8.47(2.87 \\
\text { to } 25.02) \\
\end{array}$ & $\begin{array}{r}<0.001 \\
*\end{array}$ & $\begin{array}{r}7.05(2.19 \text { to } \\
22.72) \\
\end{array}$ & $0.001 *$ \\
\hline $\begin{array}{l}\text { If you had } \\
\text { LTBI, would } \\
\text { you like to be } \\
\text { offered } \\
\text { preventive } \\
\text { therapy? } \\
\end{array}$ & & & & $\begin{array}{r}<0.001 \\
*\end{array}$ & & $0.001 *$ \\
\hline All & $\begin{array}{r}198 / 244 \\
(81 \%) \\
\end{array}$ & $\begin{array}{r}46 / 244 \\
(19 \%) \\
\end{array}$ & & & & \\
\hline Respiratory & $\begin{array}{r}11 / 23 \\
(48 \%) \\
\end{array}$ & $\begin{array}{r}12 / 23 \\
(52 \%) \\
\end{array}$ & 1.00 (Ref) & & 1.00 (Ref) & \\
\hline Other Medical & $\begin{array}{r}96 / 108 \\
(89 \%) \\
\end{array}$ & $\begin{array}{r}12 / 108 \\
(11 \%) \\
\end{array}$ & $\begin{array}{r}8.73(3.16 \\
\text { to } 24.07) \\
\end{array}$ & $\begin{array}{r}<0.001 \\
*\end{array}$ & $\begin{array}{r}10.16(3.29 \\
\text { to } 31.44) \\
\end{array}$ & $<0.001^{*}$ \\
\hline Surgery & $\begin{array}{r}24 / 27 \\
(89 \%) \\
\end{array}$ & $\begin{array}{r}3 / 27 \\
(11 \%) \\
\end{array}$ & $\begin{array}{r}8.73(2.04 \\
\text { to } 37.30) \\
\end{array}$ & $0.003 *$ & $\begin{array}{r}10.56(2.11 \\
\text { to } 52.98) \\
\end{array}$ & $0.004^{*}$ \\
\hline Other & $\begin{array}{r}67 / 86 \\
(78 \%) \\
\end{array}$ & $\begin{array}{l}19 / 86 \\
(22 \%) \\
\end{array}$ & $\begin{array}{r}3.85(1.47 \\
\text { to } 10.09) \\
\end{array}$ & $0.006^{*}$ & $\begin{array}{r}3.97(1.34 \text { to } \\
11.71) \\
\end{array}$ & $0.013 *$ \\
\hline $\begin{array}{l}\text { Do you feel you } \\
\text { need more } \\
\text { information } \\
\text { before deciding } \\
\text { to accept or } \\
\text { reject } \\
\text { preventive } \\
\text { therapy? }\end{array}$ & & & & 0.198 & & 0.397 \\
\hline All & $\begin{array}{r}185 / 264 \\
(70 \%) \\
\end{array}$ & $\begin{array}{r}79 / 264 \\
(30 \%) \\
\end{array}$ & & & & \\
\hline
\end{tabular}




\begin{tabular}{|lrrrrrr|}
\hline Respiratory & $\begin{array}{r}12 / 25 \\
(48 \%)\end{array}$ & $\begin{array}{r}13 / 25 \\
(52 \%)\end{array}$ & 1.00 (Ref) & & 1.00 (Ref) & \\
\hline Other Medical & $80 / 112$ & $32 / 112$ & $2.71(1.12$ & $0.027^{*}$ & $2.68(1.00$ to & 0.051 \\
& $(71 \%)$ & $(29 \%)$ & to 6.56$)$ & & $7.23)$ & \\
\hline Surgery & $22 / 30$ & $8 / 30$ & $2.98(0.97$ & 0.058 & $2.13(0.61$ to & 0.239 \\
& $(73 \%)$ & $(27 \%)$ & to 9.20$)$ & & $7.50)$ & \\
\hline Other & $70 / 96$ & $26 / 96$ & $2.92(1.18$ & $0.020^{*}$ & $2.49(0.91$ to & 0.076 \\
& $(73 \%)$ & $(27 \%)$ & to 7.21$)$ & & $6.83)$ & \\
\hline
\end{tabular}

$390{ }^{+}$Responses that indicated that the person filling in the questionnaire had no opinion on the topic

391 were excluded for this analysis 
392 Table 3: Characteristics of HCWs who knew and did not know the difference between 393 active and latent $\mathrm{TB}$

\begin{tabular}{|c|c|c|c|c|c|c|}
\hline Factor & $\begin{array}{c}\text { HCWs } \\
\text { Who Knew } \\
\text { The } \\
\text { Difference } \\
\text { Between } \\
\text { Active and } \\
\text { Latent TB } \\
(\%) \\
\end{array}$ & $\begin{array}{c}\text { HCWs Who } \\
\text { Did Not } \\
\text { Know The } \\
\text { Difference } \\
\text { Between } \\
\text { Active and } \\
\text { Latent TB } \\
(\%) \\
\end{array}$ & $\begin{array}{c}\text { Unadjust } \\
\text { ed OR } \\
(95 \% \mathrm{CI})\end{array}$ & $\begin{array}{c}\mathbf{p} \\
\text { value }\end{array}$ & $\begin{array}{c}\text { Adjusted } \\
\text { OR } \\
(95 \% \mathrm{CI})\end{array}$ & $\begin{array}{c}\text { Adjust } \\
\text { ed } p \\
\text { value }\end{array}$ \\
\hline All & $\begin{array}{r}242 / 306 \\
(79 \%)\end{array}$ & $\begin{array}{r}64 / 306 \\
(21 \%)\end{array}$ & & & & \\
\hline Age, $n=306$ & & & & $0.006 *$ & & $0.034 \%$ \\
\hline$\leq 30$ & $51 / 74(69 \%)$ & $23 / 74(31 \%)$ & $\begin{array}{r}1.00 \\
\text { (Ref) }\end{array}$ & & 1.0 & \\
\hline $31-40$ & $85 / 95(89 \%)$ & $10 / 95(11 \%)$ & $\begin{array}{r}3.83 \\
(1.69 \text { to } \\
8.70) \\
\end{array}$ & $0.001 *$ & $\begin{array}{r}3.32 \\
(1.23 \text { to } \\
8.99) \\
\end{array}$ & $0.008^{*}$ \\
\hline $41-50$ & $63 / 77(82 \%)$ & $14 / 77(18 \%)$ & $\begin{array}{r}2.03 \\
(0.95 \text { to } \\
4.34) \\
\end{array}$ & 0.068 & $\begin{array}{r}1.85 \\
(0.73 \text { to } \\
4.70) \\
\end{array}$ & 0.193 \\
\hline$>50$ & $43 / 60(72 \%)$ & $17 / 60(28 \%)$ & $\begin{array}{r}1.14 \\
(0.54 \text { to } \\
2.41) \\
\end{array}$ & 0.730 & $\begin{array}{r}0.85 \\
(0.33 \text { to } \\
2.19) \\
\end{array}$ & 0.735 \\
\hline Sex, n=306 & & & & 0.001* & & 0.222 \\
\hline Male & $81 / 88(92 \%)$ & $7 / 88(8 \%)$ & $\begin{array}{r}1.00 \\
\text { (Ref) }\end{array}$ & & 1.0 & \\
\hline Female & $\begin{array}{r}161 / 218 \\
(74 \%)\end{array}$ & $\begin{array}{r}57 / 218 \\
(26 \%)\end{array}$ & $\begin{array}{r}0.24 \\
(0.11 \text { to } \\
0.56) \\
\end{array}$ & & $\begin{array}{r}0.52 \\
(0.18 \text { to } \\
1.48) \\
\end{array}$ & \\
\hline Profession, $n=306$ & & & & $\begin{array}{r}<0.001 \\
*\end{array}$ & & $0.001 *$ \\
\hline Doctor & $\begin{array}{r}104 / 105 \\
(99 \%) \\
\end{array}$ & $1 / 105(1 \%)$ & $\begin{array}{r}1.00 \\
\text { (Ref) } \\
\end{array}$ & & 1.0 & \\
\hline Nurse & $\begin{array}{r}138 / 201 \\
(69 \%)\end{array}$ & $\begin{array}{r}63 / 201 \\
(31 \%)\end{array}$ & $\begin{array}{r}0.02 \\
(0.003 \text { to } \\
0.15) \\
\end{array}$ & & $\begin{array}{r}0.033 \\
(0.004 \text { to } \\
0.26) \\
\end{array}$ & \\
\hline Specialty, n=304 & & & & 0.060 & & 0.699 \\
\hline Respiratory & $25 / 28(89 \%)$ & $3 / 28(11 \%)$ & $\begin{array}{r}1.00 \\
(\text { Ref) } \\
\end{array}$ & & $\begin{array}{r}1.00 \\
\text { (Ref) } \\
\end{array}$ & \\
\hline Other medical & $\begin{array}{r}109 / 129 \\
(84 \%)\end{array}$ & $\begin{array}{r}20 / 129 \\
(16 \%)\end{array}$ & $\begin{array}{r}0.65 \\
(0.18 \text { to } \\
2.37)\end{array}$ & 0.518 & $\begin{array}{r}0.62 \\
(0.15 \text { to } \\
2.61)\end{array}$ & 0.511 \\
\hline
\end{tabular}




\begin{tabular}{|c|c|c|c|c|c|c|}
\hline Surgery & $25 / 35(71 \%)$ & $10 / 35(29 \%)$ & $\begin{array}{r}0.3(0.07 \\
\text { to } 1.22)\end{array}$ & 0.093 & $\begin{array}{r}0.59 \\
(0.13 \text { to } \\
2.73)\end{array}$ & 0.498 \\
\hline Other & $\begin{array}{r}82 / 112 \\
(73 \%)\end{array}$ & $\begin{array}{r}30 / 112 \\
(27 \%)\end{array}$ & $\begin{array}{r}0.33 \\
(0.09 \text { to } \\
1.17)\end{array}$ & 0.085 & $\begin{array}{r}0.44 \\
(0.11 \text { to } \\
1.76)\end{array}$ & 0.246 \\
\hline $\begin{array}{l}\text { Country of Birth, } \\
n=302\end{array}$ & & & & 0.229 & & 0.799 \\
\hline Australia & $\begin{array}{r}106 / 142 \\
(75 \%) \\
\end{array}$ & $\begin{array}{r}36 / 142 \\
(25 \%)\end{array}$ & $\begin{array}{r}1.00 \\
\text { (Ref) }\end{array}$ & & $\begin{array}{r}1.00 \\
\text { (Ref) }\end{array}$ & \\
\hline $\begin{array}{l}\text { Outside } \\
\text { Australia with } \\
\text { TB incidence } \\
<60 \text { per } 100 \\
000 \text { per year }\end{array}$ & $50 / 62(81 \%)$ & $12 / 62(19 \%)$ & $\begin{array}{r}1.42 \\
(0.68 \text { to } \\
2.95)\end{array}$ & 0.354 & $\begin{array}{r}0.65 \\
(0.26 \text { to } \\
1.63)\end{array}$ & 0.363 \\
\hline $\begin{array}{l}\text { Outside } \\
\text { Australia with } \\
\text { TB incidence } \\
\geq 60 \text { per } 100 \\
000 \text { per year }\end{array}$ & $82 / 98(84 \%)$ & $16 / 98(16 \%)$ & $\begin{array}{r}1.74 \\
(0.90 \text { to } \\
3.35)\end{array}$ & 0.098 & $\begin{array}{r}1.03 \\
(0.43 \text { to } \\
2.59)\end{array}$ & 0.940 \\
\hline BCG Vaccine, $n=300$ & & & & 0.088 & & 0.163 \\
\hline Yes & $\begin{array}{r}184 / 227 \\
(81 \%)\end{array}$ & $\begin{array}{r}43 / 227 \\
(19 \%)\end{array}$ & $\begin{array}{r}0.84 \\
(0.37 \text { to } \\
1.91) \\
\end{array}$ & 0.669 & $\begin{array}{r}0.69 \\
(0.25 \text { to } \\
1.92) \\
\end{array}$ & 0.471 \\
\hline No & $41 / 49(84 \%)$ & $8 / 49(16 \%)$ & $\begin{array}{r}1.00 \\
\text { (Ref) } \\
\end{array}$ & & $\begin{array}{r}1.00 \\
(\text { Ref }) \\
\end{array}$ & \\
\hline Don't know & $15 / 24(63 \%)$ & $9 / 24(37 \%)$ & $\begin{array}{r}0.32 \\
(0.11 \text { to } \\
1.0) \\
\end{array}$ & $0.050^{*}$ & $\begin{array}{r}0.39 \\
(0.11 \text { to } \\
1.41) \\
\end{array}$ & 0.149 \\
\hline $\begin{array}{l}\text { TST and/or IGRA } \\
\text { Result, } n=253\end{array}$ & & & & $\begin{array}{r}\mathbf{0 . 0 2 0} \\
*\end{array}$ & & 0.069 \\
\hline Positive & $\begin{array}{r}98 / 114 \\
(86 \%)\end{array}$ & $\begin{array}{r}16 / 114 \\
(14 \%)\end{array}$ & $\begin{array}{r}2.39 \\
(1.25 \text { to } \\
4.55) \\
\end{array}$ & $0.008 *$ & $\begin{array}{r}2.51 \\
(1.15 \text { to } \\
5.49) \\
\end{array}$ & $0.021 *$ \\
\hline Negative & $\begin{array}{r}100 / 139 \\
(72 \%) \\
\end{array}$ & $\begin{array}{r}39 / 139 \\
(28 \%) \\
\end{array}$ & $\begin{array}{r}1.00 \\
\text { (Ref) } \\
\end{array}$ & & $\begin{array}{r}1.00 \\
\text { (Ref) } \\
\end{array}$ & \\
\hline Not applicable & $44 / 53(83 \%)$ & $9 / 53(17 \%)$ & $\begin{array}{r}1.91 \\
(0.85 \text { to } \\
4.27) \\
\end{array}$ & 0.117 & $\begin{array}{r}1.41 \\
(0.53 \text { to } \\
3.80) \\
\end{array}$ & 0.494 \\
\hline
\end{tabular}




\section{Figure 1: Summary of respondents' TB screening results}

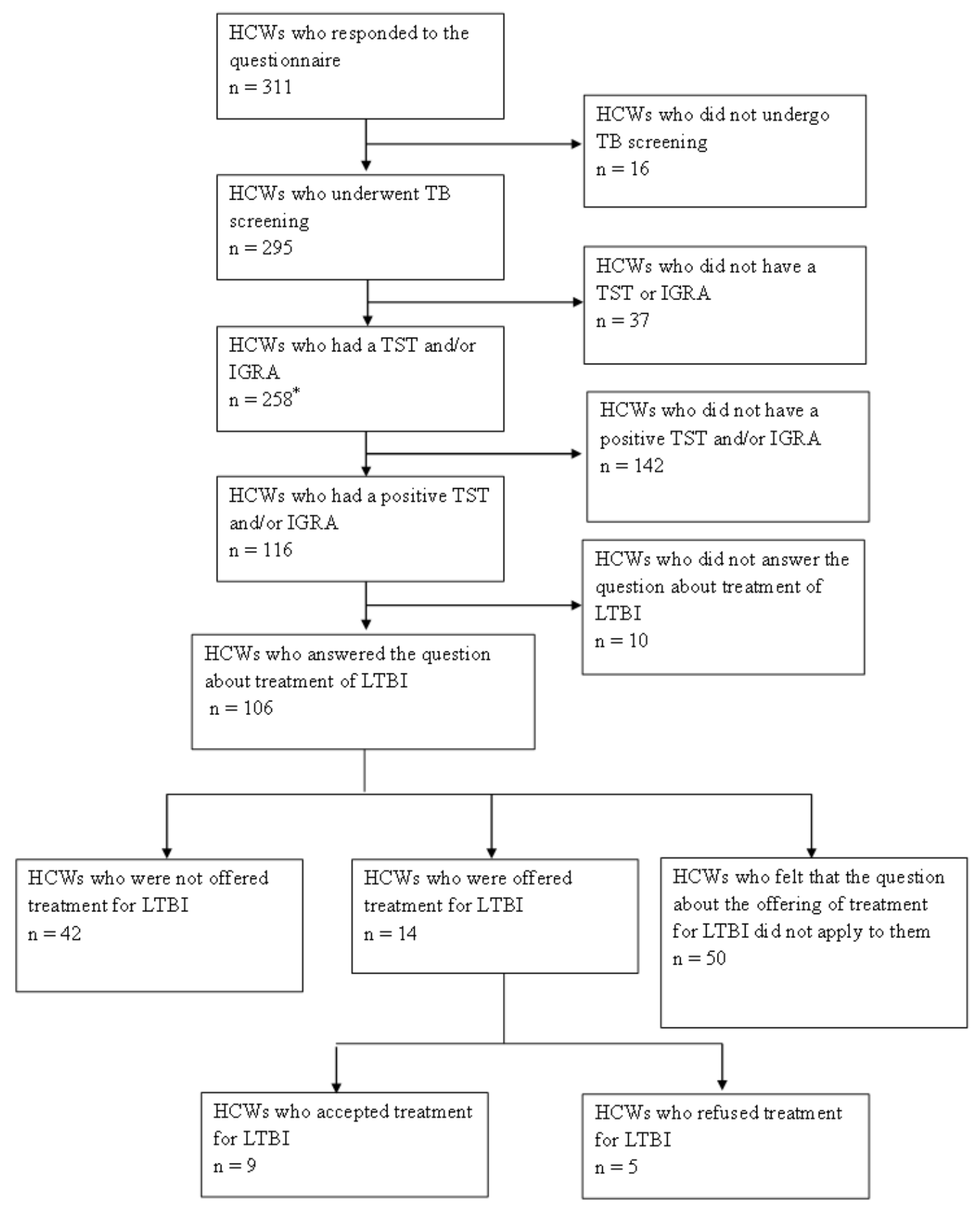

*Sixteen had both a TST and IGRA 